\title{
Effect of Book Building and Auctions on the Exit Choice between IPO and Acquisition
}

\author{
Rohan Chinchwadkar, Rama Seth \\ Indian Institute of Management Calcutta, Joka, India \\ Email: rohan.chinchwadkar@gmail.com
}

Received 10 June 2015; accepted 1 August 2015; published 4 August 2015

Copyright (C) 2015 by authors and Scientific Research Publishing Inc.

This work is licensed under the Creative Commons Attribution International License (CC BY). http://creativecommons.org/licenses/by/4.0/

c) (i) Open Access

\section{Abstract}

The choice of exit mechanism between IPOs and acquisitions is an important decision faced by entrepreneurs and private equity investors. Although the decision to go public has been studied extensively, a firm's choice between IPO and acquisition remains relatively unexplored. In this paper, we extend the existing literature by studying the effect of the type of IPO process on the decision. We introduce the two IPO methods: book building and auctions, and show how the parameters of the IPO methods affect the choice between IPOs and acquisitions. We show that for both the IPO methods, the probability of choosing IPOs decrease when cost to investors for acquiring information increases and fixed entry cost for investors increases. In the case of book building, we show that the probability of choosing IPOs decreases when the number of informed investors in the road-show increases. In the case of auctions, we show that the probability of choosing IPOs decreases when the certainty of the auction being successful decreases and the number of potential bidders increases. We analyse these extensions in two cases: when the firm is controlled by the entrepreneur and when the firm is controlled by the private equity investor. We also discuss important empirical implications which arise out of our theoretical model.

\section{Keywords}

Initial Public Offerings, Acquisitions, Private Equity, Game Theory, Signalling Games, Perfect Bayesian Equilibrium

\section{Introduction}

The decision of a firm to raise capital through initial public offerings (IPOs) has been studied extensively in literature theoretically [1]-[3], empirically [4] or [5] and in review [6]. However, many times, getting acquired by another firm is a real and an attractive option for entrepreneurs and private equity (PE) investors when they try 
to exit (at least partially) while raising external finance. The literature on the study of this choice of exit between IPO and acquisition is not very extensive. There have been few empirical studies [7]-[9], and only one theoretical analysis [10] of a firm's choice between IPO and acquisition. The objective of this paper is to extend the existing theoretical analysis of this entrepreneurial decision. We build upon the model developed by Bayar \& Chemmanur [10] and introduce two new features: (1) the concept of differential bargaining with the acquirer and (2) the two IPO methods: book building and auctions.

We consider the case of an entrepreneur managing a private firm backed by a PE investor. The entrepreneur and PE investor wish to exit from the firm (either fully or partially) due to their liquidity needs or due to the need of raising external finance for new investments needed to grow the firm. They have two options for exit: on the one hand, they can take the firm public, and sell some of their equity holdings in the firm while issuing new equity to raise external investments for the firm. In this case, the entrepreneur retains control of the firm. On the other hand, they can sell the firm to an acquirer, and sell their entire equity holding and give up control of the firm. We discuss two cases: when the firm is controlled by the entrepreneur and when the firm is controlled by the PE investor. Thus, we assume that the extent of shareholding and the term sheet ${ }^{1}$ give total control of the exit decision to either the entrepreneur or the PE investor. However, in some cases, the exit decision first involves a negotiation between the entrepreneur and the PE investor about the exit choice and then the exit decision is jointly taken by them. We find that case to be out of the scope of this study and hope to address it in future research.

Building on the model of Bayar \& Chemmanur [10], we introduce the two IPO methods of book building and auctions. Sherman [11] models IPOs in the presence of book building and uniform price auctions and analyses the effect of IPO methods on the proceeds to the firm going public. We introduce these two models into the choice between IPOs and acquisitions and derive the effect of the parameters of the IPO methods on the probability of exit through IPOs. We show that for book building and auctions, the probability of IPOs decreases when cost to acquire information for investors increases and fixed entry cost for investors increases. Specifically for book building, we show that the probability of IPOs decreases when the number of informed investors in the road-show increases. We also show that in the case of auctions, the probability of IPOs decreases when certainty of the auction being successful decreases and the number of potential bidders increases.

It is important to mention that we only consider the effect of direct costs of information production in book building and auctions on the exit choice. We have not considered the impact of the IPO processes on IPO valuation. It will be interesting extension to consider since the IPO process is known to have an effect on the way that investors value the company going public.

The rest of this paper is organized in the following manner. Section 2 introduces the Bayar \& Chemmanur [10] model and explains the assumptions and results of the model. Section 3 presents the second extension of the Bayar \& Chemmanur [10] model where we introduce IPO methods of book building and uniform price auctions and analyse the effect of the parameters of IPO methods on the choice of exit. Section 4 describes the empirical predictions of our extensions. Section 5 concludes. The Appendix provides a detailed explanation of all the symbols and variables used in the paper.

\section{Bayar and Chemmanur [10] Model of Exit Choice}

Since Bayar \& Chemmanur [10] is the first and only theoretical analysis of the choice of exit between IPOs and acquisitions, we will explain their model in detail before presenting our extensions. The crucial factor driving the exit decision is product market competition. Based on the probability of success in the product market, there are two types of firms: firms with "high" probability of success $\left(p_{H}\right)$ or "H-type firms" and firms with "low" probability of success $\left(p_{L}\right)$ or "L-type firms". The problem is set up as a one period model as shown in Figure 1. At time $t=0$, the shareholders of the firm include two types of majority investors: an entrepreneur and a PE investor. The fractions of equity held by them at time $t=0$ are denoted by $\delta_{E}$ and $\delta_{V}$ respectively and the fraction held by other minority investors is $\delta_{O}$. At this stage, the firm is in need of new investment I for one or more positive NPV projects. This investment $(I)$ can be raised in two ways, either through an IPO or through an acquisition. Both the entrepreneur and the PE investors have liquidity demands which are satisfied by a sale of a fraction of their shares, $\alpha_{E}$ and $\alpha_{V}$ respectively, out of their remaining initial equity holdings to public market investors who subscribe to the IPO. At time $t=1$, all the cash flows from the various projects are realized and the

\footnotetext{
${ }^{1}$ The term sheet is an agreement between the entrepreneur and the PE investor which is signed when the PE investor invests in the firm. It usually has clauses which give control rights to the PE investor about the timing and mechanism of exit.
} 


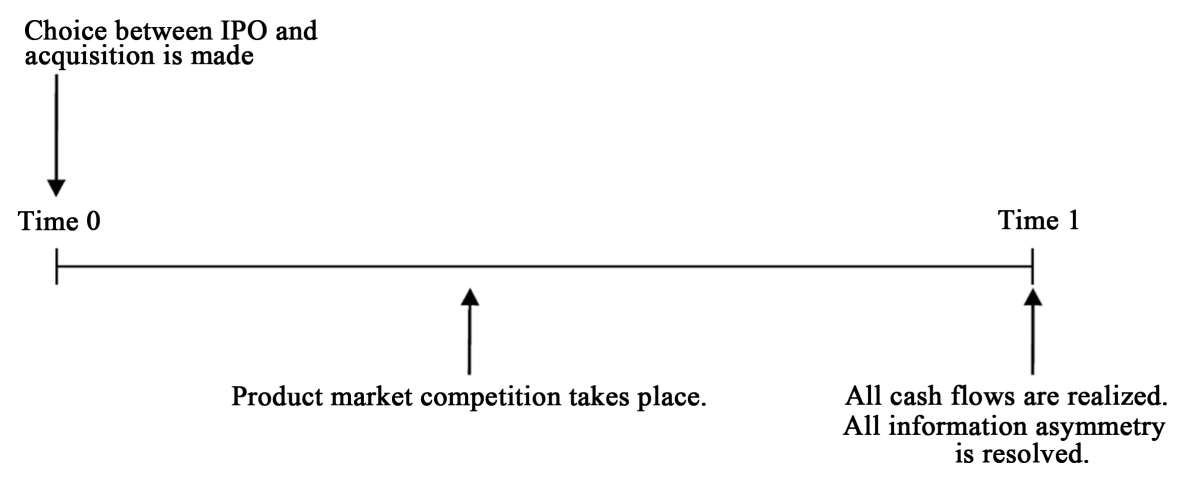

Figure 1. Sequence of events in the model, Source: Bayar \& Chemmanur (2011).

firm is liquidated (i.e. cash is returned to the investors). The final cash flows $(V)$ depend on the exit method chosen by the shareholders at time $t=0$, the degree of product market competition between time $t=0$ and time $t$ $=1$ and firm type. If the project is implemented at time $t=0$ by raising $I$, the cash flows $(V)$ can take one of two possible values at time 1 :

$$
V=\left\{\begin{array}{l}
\left(I+V_{S}\right) \text { if the firm "succeeds" by time } 1, \\
\left(I+V_{F}\right) \text { if the firm "fails" by time } 1 .
\end{array}\right.
$$

We assume that the intrinsic value of the firm is higher if it succeeds i.e. $0<V_{F}<V_{S}$. The decision is modelled as a signalling game (see Figure 2) played between the firm (entrepreneur or PE investor), the IPO market and the acquirer (" $a$ " is a variable which determines the choice between IPO and acquisition; $a=1$ indicates IPO).

After having set up the cash flows of the firm, we move on to the beliefs of the investors and strategies used by the firm. As we see, the investors believe that the proportion of H-type firms in the universe is $\theta$. The firm takes into consideration the beliefs of the investors and sets an IPO price $P_{\mathrm{ipo}}$, along with $\alpha_{E}$ and $\alpha_{V}$. The investors have to decide whether to bid for the IPO or not. It is assumed that there is no information asymmetry between the acquirer and the firm i.e. the acquirer is able to correctly assess the type of the firm. Since the acquirer has considerable bargaining power, it is assumed that he will pay only a fraction $(\rho)$ of the intrinsic net present value of the firm $\left(V_{A}\right)$ to the target firm's insiders.

\subsection{The Entrepreneur's Objective Function}

We know that if the firm goes public, the entrepreneur sells a fraction $\left(\alpha_{E}\right)$ of his shares to satisfy his personal liquidity requirements and retains private benefits of control.

However, if the firm is acquired at time $t=0$, then he has to give up private benefits of control. Thus, we see that the objective of the entrepreneur in making the exit decision at time $t=0$ is to maximize the sum of cash flow received at time $t=0$ from selling a fraction of equity $\left(\alpha_{E}\right)$ in the firm, the expected cash flow at time $t=1$, and the total estimated value of the private benefits of control accruing to him.

\subsection{The PE investor's Objective Function}

Similarly, if the firm goes public at time $t=0$, the PE investor sells a fraction $\left(\alpha_{V}\right)$ of his shares to satisfy personal liquidity requirements but does not gain any private benefits of control as the entrepreneur receives. On the other hand, if the firm is acquired at time $t=0$, he receives no private benefits. Thus, we see that the objective of the private equity investor in making the exit decision at time $t=0$ is to maximize the sum of cash flow received at time $t=0$ from selling a fraction of equity in the firm and the expected cash flow at time $t=1$.

\subsection{The Acquirer}

It is assumed that there is no information asymmetry between the acquirer and the firm i.e. the acquirer is able to correctly assess the type of the firm. Since the acquirer has considerable bargaining power, he will pay only a fraction $(\rho)$ of the intrinsic net present value of the firm to the target firm's insiders. After the takeover, the ac- 


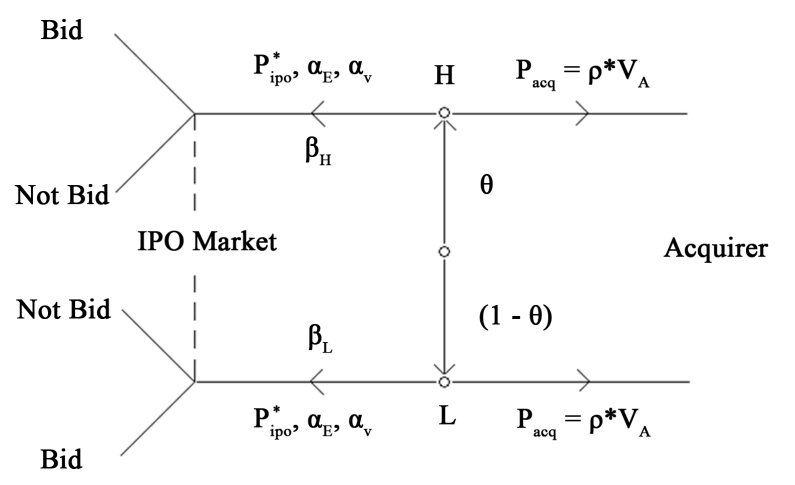

Figure 2. Signalling game between entrepreneur, IPO market and acquirer in Bayar and Chemmanur (2011) [10].

quirer owns the entire firm, provides the capital I for new investment, and the firm's management is replaced. For both the firms, there is synergy created due to the acquisition such that the probability of success in competition with incumbent firms increases to $p_{A}$, where we assume that $1>p_{A}>p_{H}>p_{L}$. Here Bayar and Chemmanur [10] assume that the increase in the probability of success in product market competition as a result of an acquisition is higher for a L-type firm. Thus, the expected time 1 cash flow for the firms after an acquisition is then given by $\left[I+p_{A} V_{S}+\left(1-p_{A}\right) V_{F}\right]$. Thus, intrinsic value of the firm pre-acquisition is $V_{A}$, where, $V_{A}=p_{A} V_{S}+(1-$ $\left.p_{A}\right) V_{F}$. Thus, since the expected value of the firm is $V_{A}$ and due to bargaining power, acquirer will pay only a fraction $(\rho)$, the acquirer ends up paying a value $\rho * V_{A}$ to both the firms.

\subsection{The IPO Market}

If the firm decides to go for an IPO, a fraction $\gamma$ of the firm is offered to the public market investors who subscribe for the IPO. To satisfy their liquidity demands, the entrepreneur and the PE investor sell fractions $\alpha_{V}$ and $\alpha_{E}$, respectively, of their remaining shareholdings $\delta_{E}(1-\gamma)$ and $\delta_{V}(1-\gamma)$, respectively, as part of the IPO. The number of shares outstanding for the firm is normalized to 1 , so that the fraction of shares offered in the IPO becomes $\gamma+\left(\delta_{E} \alpha_{E}+\delta_{V} \alpha_{V}\right)(1-\gamma)$. As discussed earlier, price $P_{\text {ipo }}$ is decided by the firm keeping in mind the beliefs of the investors. Also, the prior probability assessment of IPO market investors is $\operatorname{Pr}(q=H)=\theta$ and $\operatorname{Pr}(q=L)=(1-\theta)$. These probabilities are updated by Bayes' rule depending on the strategies of the types of firms.

\subsection{The Results of the Model}

Using the concept of Perfect Bayesian Equilibrium applied to the above model, Bayar and Chemmanur [10] show that for the H-type firms, the payoff from choosing an IPO is always larger than the payoff from choosing an acquisition. However, for L-type firms, it is possible for the payoffs from IPO and acquisition to be equal. Thus, they derive the following semi-separating equilibrium: H-type firms will always choose to go for an IPO i.e. pure strategy and L-type firms will choose to go for an IPO with probability $\beta_{L}$ and for acquisition with probability $\left(1-\beta_{L}\right)$ i.e. mixed strategy, where $\beta_{L}$ is given by:

$$
\beta_{L}=\left\{\frac{\theta *\left[\left(I+V_{H}\right)-P_{\mathrm{IPO}}^{*}\right]}{(1-\theta) *\left[P_{\mathrm{IPO}}^{*}-\left(I+V_{L}\right)\right]}\right\}
$$

\section{Extensions: IPO Methods of Book Building and Auctions}

Since the investor base in an IPO is large and diversified, information asymmetry between a firm and the investors is known to exist between IPO investors and the issuing firm. Bayar \& Chemmanur (2011) address this problem using pre-existent beliefs of the IPO investors about the type of the firms. As we have seen, they assume that investors believe that the proportion of H-type firms in the universe of firms is $\theta$ and firms set equilibrium IPO prices taking into account the beliefs of the investors. Thus, their model assumes that firms react to information asymmetry only through the equilibrium IPO price at the time of the IPO. They assume that there 
are no mechanisms of signaling through which firms try to resolve the information asymmetry problem before the IPO. However, this is not an accurate description of reality. Firms issuing IPOs are known to use either of the two mechanisms: (i) book building (this is the only method allowed by regulation in India) and (ii) auction. Famous examples of IPOs in USA which used the two methods are Facebook, which used the book building method and Google, which used the auction method. As we would expect, each of these mechanisms involve costs which are termed as costs of information production or floatation costs and they depend upon the parameters of the mechanism being used. Since firms undertake these costs to reduce information asymmetry, they reduce the proceeds of the IPO. Since presence of IPO mechanisms reduce the payoff to the issuing firm, it is important to study their role in the exit decision between IPOs and acquisitions. Sherman [11] presents an analysis of the theoretical models of IPOs using book building and auctions. We incorporate the models of the IPO mechanism into the Bayar \& Chemmanur [10] model of exit choice and derive the effect of the parameters of book building and auctions on the probability of exit through IPOs as opposed to acquisitions. We keep all the other assumptions of their model intact and analyse the same semi-separating equilibrium for the case of an entrepreneur-controlled firm. We do not perform the same analysis for PE-investor-controlled firm because it yields similar results.

\subsection{The Common Environment for Book Building and Auctions}

There are certain common conditions which Sherman [11] assumes for both the IPO models. The market consists of $\mathrm{N}$ investors who have an access to capital and information (informed investors). Since both the IPO models involve a cost of information production, investors much pay $C(\alpha)$ to purchase information which reveals the type of firm (either H-type or L-type) with probability of $\alpha$ and gives a neutral signal M with probability of $(1-\alpha)$. It is assumed that the probability of receiving a false signal is zero. The mathematical properties of $C(\alpha)$ are: it is twice differentiable, strictly convex and strictly increasing for a value of $\alpha \in(0,1)$. Apart from the cost of information, each investor faces a "fixed entry cost" of $e>0$ if he wishes to participate in the IPO. Although it seems as if investors are carrying the burden of information production, these costs which ultimately reduce the equilibrium IPO price set by the firm, thus signifying that information production costs are actually borne by the issuing firm to reduce information asymmetry.

\subsection{The Book Building Model}

In the book building method of IPOs, the issuing firm hires an underwriter (investment bank) to help place its shares with different types of investors. The underwriter selects $K$ risk-neutral and potentially informed investors to evaluate the offering in a road show. The model assumes that the underwriter has the flexibility to choose allocation and price for each investor depending on the quality of the signal reported by them and other investors. Given these parameters of the book building process, Sherman [11] calculates the total proceeds (equivalent to $P_{\mathrm{IPO}}$ in Bayar \& Chemmanur [10] model) to the issuing firm as:

$$
P_{\mathrm{IPO}}=I+\operatorname{Pr}(q=H \mid a=1) V_{H}+\operatorname{Pr}(q=L \mid a=1) V_{L}-K[C(\alpha)+e]
$$

We can see that this expression is similar to the equilibrium IPO price in the [10] model but includes an extra term " $K[C(\alpha)+e]$ " which represents the cost of information production in the book building process. We will incorporate this in the Bayar \& Chemmanur [10] semi-separating equilibrium and derive the relationship between the IPO probability of L-type firm, $\beta$ and the book building parameters $K, C(\alpha)$ and $e$. This analysis will help us understand how parameters of the IPO book building process affect the issuing firm's decision to choose an IPO over an acquisition.

\subsection{The Auction Models}

Sherman [11] introduces two types of multi-unit, sealed-bid auctions: a uniform price auction and a discriminatory auction. He goes on to show that the expected IPO proceeds in both types of auctions are the same, thus we will only discuss the uniform price auctions in this paper. The issuing firm wants to auction $X$ number of shares and the lowest bid possible is the price of shares of a L-type firm. This is equivalent to a reserve price which is typically set in auctions. There are $N$ potential bidders such that $N>X$. Each of the bidders chooses $p$, which is that probability that he will enter the auction and $\alpha$, which is the accuracy of the information purchased. There 
are two basic rules of a uniform price auction: (i) if there are $(X+1)$ or more bids, all $X$ bidding winners will pay the $(X+1)^{\text {st }}$ bid, else, (ii) if there are less than $(X+1)$ bids, all bidders pay the reservation price which is the value of L-type shares. Since it is not necessary that each potential bidder will actually bid, there is a probability that the auction will be incomplete i.e. fewer that $X$ shares will be sold. This uncertainty is a significant disadvantage of using auctions instead of book building. Given these parameters of the uniform price auction process, Sherman [11] calculates the total proceeds (equivalent to $P_{\mathrm{IPO}}$ in Bayar \& Chemmanur [10] model) to the issuing firm as:

$$
P_{\mathrm{IPO}}=\left[I+\operatorname{Pr}(q=H \mid a=1) V_{H}+\operatorname{Pr}(q=L \mid a=1) V_{L}\right] *\left(1-P_{X}\right)-p N[C(\alpha)+e]
$$

where, $P_{X}$ is the probability that the auction will be unsuccessful i.e. lower than $X$ shares will be sold (due to less than optimal bidders bidding) and is given by:

$$
P_{x}=\sum_{i=0}^{X-1} P(\text { entry }=i)\left(1-\frac{i}{X}\right)(\text { Sherman }(2005))
$$

where $P($ entry $=i)$ is the entry probability of the $i^{\text {th }}$ bidder

Once again, we see that this IPO price is similar to Bayar \& Chemmanur [10] with the addition of two terms: (i) “ $p N[C(\alpha)+e]$ ” which is the cost of information production and (ii) " $\left(1-P_{x}\right)$ ” which is the probability that the auction with be successful. We will incorporate this in the Bayar \& Chemmanur [10] semi-separating equilibrium and derive the relationship between the IPO probability of L-type firm, $\beta$ and the auction parameters $p$, $N,\left(1-P_{x}\right), C(\alpha)$ and $e$. This analysis will help us understand how parameters of the IPO auction process affect the issuing firm's decision to choose an IPO over an acquisition.

\subsection{Equilibrium of the Book Building Model}

In this section, we incorporate the IPO book building process in the Bayar \& Chemmanur [10] and analyse the semi-separating equilibrium which they derive. In the semi-separating equilibrium, we know that H-type firms always choose to go public whereas L-type firms choose IPO with probability $\beta_{L}$ and acquisition with probability $\left(1-\beta_{L}\right)$. We will derive the equilibrium in the presence of book building and analyse the effect of the book building parameters on $\beta_{L}$. The introduction of book building only affects the equilibrium IPO price set by the firms, does not affect the indifference conditions and hence does not affect the equilibrium derived by Bayar \& Chemmanur [10].

Proposition 1: Choice between IPO and Acquisition in an entrepreneur-controlled firm in the presence of book building

In the presence of book building process for IPOs:

1) The entrepreneur takes the H-type firm public with probability 1.

2) The L-type firm goes public with probability $\beta_{L}$ and for an acquisition with probability $\left(1-\beta_{L}\right)$ such that,

$$
\beta_{L}=\left\{\frac{\theta *\left[\left(I+V_{H}\right)-K(C(\alpha)+e)-P_{I E}^{*}\right]}{(1-\theta) *\left(P_{I E}^{*}-\left(I+V_{L}\right)-K(C(\alpha)+e)\right)}\right\}
$$

The equilibrium IPO price $P_{I E}^{*}$ is given by Equation (10)

\section{Proof.}

From Equation (2), we see that

$$
P_{\mathrm{IPO}}=I+\operatorname{Pr}(q=H \mid a=1) V_{H}+\operatorname{Pr}(q=L \mid a=1) V_{L}-K[C(\alpha)+e]
$$

Since the investors' beliefs are updated using Bayes' rule, we get,

$$
\begin{aligned}
& \operatorname{Pr}(q=H \mid a=1)=\frac{\theta}{\theta+\beta_{L} *(1-\theta)} \\
& \operatorname{Pr}(q=L \mid a=1)=\frac{\beta_{L} *(1-\theta)}{\theta+\beta_{L} *(1-\theta)}
\end{aligned}
$$


Using Equations (2), (6) and (7), we get,

$$
P_{I E}=I+\frac{\theta}{\theta+\beta_{L} *(1-\theta)} * V_{H}+\frac{\beta_{L} *(1-\theta)}{\theta+\beta_{L} *(1-\theta)} * V_{L}-K[C(\alpha)+e]
$$

Rearranging Equation (8), we derive the probability of a L-type firm choosing an IPO as mentioned in proposition 1.

Next, we analyse the available payoffs to the L-type firm and derive the equilibrium indifference condition. Since L-type firms use a mixed strategy in equilibrium, the indifference condition in Equation (9) holds.

$$
\delta_{E}\left(\alpha_{E}+\left(1-\alpha_{E}\right) \frac{I}{P_{I E}^{*}}\right)\left(P_{I E}^{*}-V_{L}-I\right)+B=\delta_{E}\left(I+\rho_{L} V_{A}-\left(I+V_{L}\right)\right)
$$

Solving Equation (9) which is quadratic in the equilibrium IPO price $\left(P_{I E}^{*}\right)$, we derive the expression for $P_{I E}^{*}$ in an entrepreneur-controlled firm.

$$
P_{I E}^{*}=\frac{Q+\alpha_{E} V_{L}-\left(1-2 \alpha_{E}\right) I+\sqrt{\left(Q+\alpha_{E} V_{L}-\left(1-2 \alpha_{E}\right) I\right)^{2}+4 \alpha_{E}\left(1-\alpha_{E}\right) I\left(I+V_{L}\right)}}{2 \alpha_{E}}
$$

where,

$$
Q=\rho V_{A}-V_{L}-\frac{B}{\delta_{E}}
$$

Proposition 2: Statics of the exit choice between IPO and Acquisition in an entrepreneur controlled firm in the presence of book building

The probability of a L-type firm choosing an IPO $\left(\beta_{L}\right)$ : (a) decreases when the number of informed investors $(K)$ in the road show increases; $(b)$ decreases when the cost of acquiring information $(C(\alpha))$ increases; $(c)$ decreases when the fixed entry cost per investor (e) increases.

Proof.

To derive the relationship between probability of choosing IPO $\left(\beta_{L}\right)$ and the parameters of the book building process, we partially differentiate $\beta_{L}$ in Equation (5) with respect to $K, C(\alpha)$ and $e$. Proposition 2(a) signifies the effect of the road show on the exit decision. An increase in number of road show investors signifies increase in time and cost required for the book building process to be successful. Thus, if an entrepreneur knows ex-ante, that a large number of road show investors are necessary to make the IPO successful, the IPO option becomes less attractive to him. Proposition 2(b) discusses the effect of cost of information acquisition on the exit choice. The cost of acquiring information $(C)$ will increase as the desired level of information accuracy $(\alpha)$ increases. Thus, if the entrepreneur and investors desire a high level of information and pricing accuracy, the cost of information production will increase, thus making IPO a less attractive option. This result signifies that in an IPO market with severe information asymmetry, the attractiveness of an IPO as compared to an acquisition reduces significantly. Proposition 2(c) purely reflects the effect of the fixed cost of participating in an IPO on the exit choice. If the fixed cost of participation per investor is high, IPO becomes less attractive than acquisition.

$$
\begin{gathered}
\frac{\partial \beta_{L}}{\partial K}=\frac{-\theta(C(\alpha)+e)\left(V_{H}-V_{L}\right)}{(1-\theta)\left\{\left[P_{I E}^{*}-\left(I+V_{L}\right)-K(C(\alpha)+e)\right]\right\}^{2}}<0 \\
\frac{\partial \beta_{L}}{\partial C(\alpha)}=\frac{-\theta K\left(V_{H}-V_{L}\right)}{(1-\theta)\left\{\left[P_{I E}^{*}-\left(I+V_{L}\right)-K(C(\alpha)+e)\right]\right\}^{2}}<0 \\
\frac{\partial \beta_{L}}{\partial e}=\frac{-\theta K\left(V_{H}-V_{L}\right)}{(1-\theta)\left\{\left[P_{I E}^{*}-\left(I+V_{L}\right)-K(C(\alpha)+e)\right]\right\}^{2}}<0
\end{gathered}
$$




\subsection{Equilibrium of the Auction Model}

In this section, we incorporate the uniform price auction process in the Bayar \& Chemmanur [10] and analyse the semi-separating equilibrium which they derive. In the semi-separating equilibrium, we know that H-type firms always choose to go public whereas L-type firms choose IPO with probability $\beta_{L}$ and acquisition with probability $\left(1-\beta_{L}\right)$. We will derive the equilibrium in the presence of uniform price auction and analyse the effect of the auction parameters on $\beta_{L}$. The introduction of book building only affects the equilibrium IPO price set by the firms, does not affect the indifference conditions and hence does not affect the equilibrium derived by Bayar \& Chemmanur [10].

Proposition 3: Choice between IPO and acquisition in an entrepreneur-controlled firm in the presence of uniform price auctions

In the presence of uniform price auction for IPOs:

1) The entrepreneur takes the H-type firm public with probability 1.

2) The L-type firm goes public with probability $\beta_{L}$ and for an acquisition with probability $\left(1-\beta_{L}\right)$ such that,

$$
\beta_{L}=\left\{\frac{\theta *\left[\left(I+V_{H}\right)\left(1-P_{x}\right)-p N(C(\alpha)+e)-P_{I E}^{*}\right]}{(1-\theta) *\left(P_{I E}^{*}-\left(I+V_{L}\right)\left(1-P_{x}\right)-p N(C(\alpha)+e)\right)}\right\}
$$

The equilibrium IPO price $P_{I E}^{*}$ is given by Equation (10)

Proof.

From Equation (2), we see that

$$
P_{\mathrm{IPO}}=\left[I+\operatorname{Pr}(q=H \mid a=1) V_{H}+\operatorname{Pr}(q=L \mid a=1) V_{L}\right] *\left(1-P_{x}\right)-p N[C(\alpha)+e]
$$

Since the investors' beliefs are updated using Bayes' rule, we get from Equations (6) and (7),

$$
\begin{aligned}
& \operatorname{Pr}(q=H \mid a=1)=\frac{\theta}{\theta+\beta_{L} *(1-\theta)} \\
& \operatorname{Pr}(q=L \mid a=1)=\frac{\beta_{L} *(1-\theta)}{\theta+\beta_{L} *(1-\theta)}
\end{aligned}
$$

Using Equations (3), (6) and (7), we get,

$$
P_{I E}=\left[I+\frac{\theta}{\theta+\beta_{L} *(1-\theta)} * V_{H}+\frac{\beta_{L} *(1-\theta)}{\theta+\beta_{L} *(1-\theta)} * V_{L}\right]\left(1-P_{x}\right)-p N[C(\alpha)+e]
$$

Rearranging Equation (16), we derive the probability of a L-type firm choosing an IPO as mentioned in proposition 3.

Next, we analyse the available payoffs to the L-type firm and derive the equilibrium indifference condition. Since L-type firms use a mixed strategy in equilibrium, the indifference condition in Equation (9) holds. Following that, we see that the equilibrium IPO price is given by Equation (10).

Proposition 4: Statics of the exit choice between IPO and acquisition in an entrepreneur controlled firm in the presence of uniform price auction

The probability of a L-type firm choosing an IPO $\left(\beta_{L}\right)$ : (a) decreases when the number of potential bidders $(N)$ in the auction increases; $(b)$ increases when the certainty of the auction being successful $\left(1-P_{x}\right)$ increases; $(c)$ decreases when the cost of acquiring information $(C(\alpha))$ increases; $(d)$ decreases when the fixed entry cost per investor (e) increases.

\section{Proof.}

Proposition 4(a) signifies the effect of the number of potential bidders on the exit decision. We know that each participating bidder has to pay a fixed fee of "e". Thus, if more bidders participate, the total fixed cost " $N^{*} \mathrm{e}$ " increases, thus reducing the IPO price which can be set by the firm. Also, Sherman [11] mentions that in the uniform price auctions, the increase in number of potential bidders $(N)$ causes either the increase in variance in the number of entrants or decrease in the expected number of entrants, or both. This adversely affects the total expected proceeds from the IPO. Proposition 4(b) analyses the effect of uncertainty of the success of the auction 
on the exit decision. If the certainty that the auction will be successful i.e. the IPO offering is fully subscribed by the bidders, is high, then the entrepreneur is more likely to prefer an IPO over acquisition. Proposition 4(c) discusses the effect of cost of information acquisition on the exit choice and proposition 4(d) purely reflects the effect of the fixed cost of participating in an IPO on the exit choice. If the fixed cost of participation per investor is high, IPO becomes less attractive than acquisition.

To derive the relationship between probability of choosing IPO $\left(\beta_{L}\right)$ and the parameters of the book building process, we partially differentiate $\beta_{L}$ in Equation (15) with respect to $K, C(\alpha)$ and $e$.

$$
\begin{gathered}
\frac{\partial \beta_{L}}{\partial N}=\frac{-\theta p(C(\alpha)+e)\left(V_{H}-V_{L}\right)\left(1-P_{x}\right)}{(1-\theta)\left\{\left[P_{I E}^{*}-\left(I+V_{L}\right)-p N(C(\alpha)+e)\right]\right\}^{2}}<0 \\
\frac{\partial \beta_{L}}{\partial\left(1-P_{x}\right)}=\frac{\theta\left(V_{H}-V_{L}\right)\left[P_{I E}^{*}+p N(C(\alpha)+e)\right]}{(1-\theta)\left\{\left[P_{I E}^{*}-\left(I+V_{L}\right)-p N(C(\alpha)+e)\right]\right\}^{2}}>0 \\
\frac{\partial \beta_{L}}{\partial C(\alpha)}=\frac{-\theta p N\left(V_{H}-V_{L}\right)\left(1-P_{x}\right)}{(1-\theta)\left\{\left[P_{I E}^{*}-\left(I+V_{L}\right)-p N(C(\alpha)+e)\right]\right\}^{2}}<0 \\
\frac{\partial \beta_{L}}{\partial e}=\frac{-\theta p N\left(V_{H}-V_{L}\right)\left(1-P_{x}\right)}{(1-\theta)\left\{\left[P_{I E}^{*}-\left(I+V_{L}\right)-p N(C(\alpha)+e)\right]\right\}^{2}}<0
\end{gathered}
$$

Thus, we see that the sign of each partial derivative is consistent with the relationships mentioned in propositions 4(a) to 4(d).

\section{Empirical Implications}

In this section we describe the empirical implications of our extensions of the Bayar \& Chemmanur (2011) model.

\subsection{Effect of Cost of Information on Exit Choice}

In the presence of IPO methods like book building and auctions, we observe that the probability of choosing IPOs reduces as the cost of information production increases. Thus, we predict that the ratio of IPOs to acquisitions should be greater in markets where the information asymmetry problem is severe. We know that developed markets such as USA have many transparent market mechanisms to reduce information asymmetry whereas the information asymmetry problem is severe in an emerging market like India. Thus, our model predicts that the ratio of IPOs to acquisitions should be greater in USA than in India. This prediction of our model is supported by data. We see from Bayar \& Chemmanur [9] that the ratio is IPOs to acquisitions in USA from 2004 to 2007 is close to 1 , whereas, the ratio of IPOs to acquisitions in India from 2004 to 2007 is always less than $0.5^{2}$. The Wall Street Journal ${ }^{3}$ has also reported that the quantum of IPOs in USA has reduced since the introduction of the Sarbanes-Oxley Act of 2002, which has increased the cost of going public due to increased governance and disclosure requirements.

\subsection{Effect of Scale of Road Show on Exit Choice}

In the presence of book building, we see that the probability of choosing IPOs reduces as the number of road show investors increases. If a large number of investors are necessary to make a road show successful, it increases the cost of going public. Thus, our model predicts that the ratio of IPOs to acquisitions should be lower in markets where the size and scale of the road show are large. We know that firms going public in developed markets like USA will typically conduct their road shows only in USA and other developed markets like UK

\footnotetext{
${ }^{2}$ Venture Intelligence database.

${ }^{3}$ See The Wall Street Journal ((Feb. 21, 2005), "More Companies Pulling Deals to Be Acquired”): "From the perspective of a small company readying itself to go public, getting acquired also avoids an after-market expense: the cost of complying with the Sarbanes-Oxley Act, which re-quires public companies to audit their internal controls, from inventory tracking to the security of their competitive systems.”
} 
and Europe. However, firms going public in emerging markets like India will typically conduct their road shows in India, other emerging markets like China and in developed markets like USA, UK and Europe. Thus, we see that road shows of emerging market firms need to be on a larger scale than those in developed markets. Thus, our model predicts that ratio of IPOs to acquisitions in developed markets should be higher than that in emerging markets.

\section{Conclusion}

In this paper, we have analysed the choice of exit between IPOs and acquisitions which is faced by entrepreneurs and PE investors. We provide an extension to the first theoretical model addressing this question [10] by studying the effect of two IPO methods of book building and auctions. In the presence of IPO mechanisms, we show that H-type firms will go public with probability 1, a result which is consistent with Bayar \& Chemmanur [10]. However, we predict that probability of L-type firm choosing an IPO reduces as: (i) the cost of information production increases; (ii) fixed entry cost per investor increases; (iii) number of road show investors in book building increases; (iv) number of potential bidders in the uniform price auction increases; and (v) certainty of the uniform price auction decreases. Our extensions present certain empirical implications, some of which are supported by observed data.

\section{References}

[1] Spiegel, M. and Tookes, H. (2007) Dynamic Competition, Innovation and Strategic Financing. Working Paper.

[2] Boot, A.W.A., Gopalan, R. and Thakor, A.V. (2006) The Entrepreneur's Choice between Private and Public Ownership. Journal of Finance, 61, 803-836. http://dx.doi.org/10.1111/j.1540-6261.2006.00855.X

[3] Chemmanur, T.J. and Fulghieri, P. (1999) A Theory of the Going-Public Decision. Review of Financial Studies, 12, 249-279. http://dx.doi.org/10.1093/rfs/12.2.249

[4] Pagano, M., Panetta, F. and Zingales, L. (1998) Why Do Companies Go Public? An Empirical Analysis. Journal of Finance, 53, 27-64. http://dx.doi.org/10.1111/0022-1082.25448

[5] Chemmanur, T.J., He, S. and Nandy, D. (2010) The Going-Public Decision and the Product Market. Review of Financial Studies, 23, 1855-1908. http://dx.doi.org/10.1093/rfs/hhp098

[6] Ritter, J.R. and Welch, I. (2002) A Review of IPO Activity, Pricing, and Allocations. The Journal of Finance, 57, 1795-1828. http://dx.doi.org/10.1111/1540-6261.00478

[7] Brau, J.C., Francis, B. and Kohers, N. (2003) The Choice of IPO versus Takeover: Empirical Evidence. Journal of Business, 76, 583-612. http://dx.doi.org/10.1086/377032

[8] Poulsen, A.B. and Stegemoller, M. (2008) Moving from Private to Public Ownership: Selling out to Public Firms versus Initial Public Offerings. Financial Management, 37, 81-101. http://dx.doi.org/10.1111/j.1755-053X.2008.00005.x

[9] Bayar, O. and Chemmanur, T.J. (2012) What Drives the Valuation Premium in IPOs versus Acquisitions? An Empirical Analysis. Journal of Corporate Finance, 18, 451-475. http://dx.doi.org/10.1016/j.jcorpfin.2012.01.007

[10] Bayar, O. and Chemmanur, T.J. (2011) IPOs versus Acquisitions and the Valuation Premium Puzzle: A Theory of Exit Choice by Entrepreneurs and Venture Capitalists. Journal of Financial and Quantitative Analysis, 46, 1755-1793. http://dx.doi.org/10.1017/S0022109011000408

[11] Sherman, A. (2005) Global Trends in IPO Methods: Book Building versus Auctions with Endogenous Entry. Journal of Financial Economics, 78, 615-649. http://dx.doi.org/10.1016/j.jfineco.2004.09.005 
Appendix A: Description of the Variables

\begin{tabular}{|c|c|}
\hline Variable & Description \\
\hline$p_{H}$ & Probability of success in the product market of the H-type firm \\
\hline$p_{L}$ & Probability of success in the product market of the L-type firm \\
\hline$\delta_{E}$ & Fraction of initial equity in the firm held by the entrepreneur \\
\hline$\delta_{V}$ & Fraction of initial equity in the firm held by the private equity investor \\
\hline$\delta_{O}$ & Fraction of initial equity in the firm held by the other minority investors \\
\hline$I$ & Investment needed by the firm at time $t=0$ \\
\hline$\alpha_{E}$ & Fraction of shares sold in the IPO by the entrepreneur for liquidity needs \\
\hline$\alpha_{V}$ & Fraction of shares sold in the IPO by the private equity investor for liquidity needs \\
\hline$V$ & Expected value of the firm at time $t=1$ \\
\hline$V_{S}$ & Value of the firm at time $t=1$ if the firms succeeds \\
\hline$V_{F}$ & Value of the firm at time $t=1$ if the firms fails \\
\hline$V_{H}$ & Expected value of a $\mathrm{H}$-type firm at time $t=1$ if the firm chooses an IPO at time $t=0$ \\
\hline$V_{L}$ & Expected value of a L-type firm at time $t=1$ if the firm chooses an IPO at time $t=0$ \\
\hline$P_{\text {ipo }}^{*}$ & Equilibrium IPO price set by the issuing firm at time $t=0$ \\
\hline$\rho$ & Fraction of the intrinsic value of the firm paid by the acquirer i.e. bargaining power of the acquirer \\
\hline$V_{A}$ & Value of the firm at time $t=1$ if it chooses acquisition at time $t=0$ \\
\hline$p_{A}$ & Probability of success in the product market of a firm after acquisition \\
\hline$\gamma$ & Fraction of shares offered to the new shareholders in an IPO \\
\hline$\theta$ & Fraction of H-type firms in the universe of firms as perceived by IPO market investors \\
\hline$\beta_{H}$ & Probability that a H-type firm will choose an IPO at time $t=0$ \\
\hline$\beta_{L}$ & Probability that a L-type firm will choose an IPO at time $t=0$ \\
\hline$P_{\text {acq }}$ & Acquisition price paid by the acquirer \\
\hline$P_{I E}^{*}$ & Equilibrium IPO price set by the issuing firm at time $t=0$ if the firm is controlled by the entrepreneur \\
\hline$P_{I V}^{*}$ & Equilibrium IPO price set by the issuing firm at time $t=0$ if the firm is controlled by the PE investor \\
\hline$B$ & Private benefits of controlled enjoyed by the entrepreneur \\
\hline$C(\alpha)$ & Cost of acquiring information about the type of firm which has an accuracy of $\alpha$ \\
\hline$e$ & Fixed cost per investor to participate in the IPO process \\
\hline$K$ & Number of informed investors which the underwriter selects for a road show in the book building process \\
\hline$p$ & Probability that a participating investor will actually bid in the IPO auction, called entry probability \\
\hline$N$ & Number of potential bidders in the IPO auction \\
\hline$X$ & Number of shares offered in the IPO auction \\
\hline$P_{x}$ & Probability that the IPO auction will be unsuccessful i.e. less than $X$ shares sold \\
\hline
\end{tabular}

